\title{
Plasma spraying of an indigenous yttria stabilized zirconia powder prepared by the sol-gel technique
}

\author{
S V JOSHI, M P SRIVASTAVA, M CHATTERJEE*, J RAY*, \\ A CHATTERJEE* and D GANGULI* \\ Defence Metallurgical Research Laboratory, Hyderabad 500258, India \\ *Central Glass and Ceramic Research Institute, Calcutta 700032, India \\ MS received 4 March 1992; revised 30 April 1992
}

\begin{abstract}
An indigenous sol-gel derived yttria-partially stabilized zirconia (Y-PSZ) powder has been characterized and its suitability for plasma spraying applications evaluated. The powder, determined to have about $5.1 \%$ yttria content, predominantly consisted of spherical particles with an average equivalent particle diameter close to $25 \mu \mathrm{m}$. Furthermore, it was found that the powder did not contain any particles $>50 \mu \mathrm{m}$, which is considered the ideal upper size limit for spray-grade ceramic powders in order to ensure complete melting during spraying. The sol-gel produced powder exhibited good flow characteristics and the plasma sprayed coatings developed using this powder were also found to have excellent thermal shock resistance. The corresponding results obtained using an imported Y-PSZ powder are also presented for the purpose of comparison.
\end{abstract}

Keywords. Plasma spraying; sol-gel technique; yttria-stabilized-zirconia; thermal barrier coatings.

\section{Introduction}

The advent of protective coatings to enhance surface properties of engineering components represents one of the most significant achievements of materials technology in the past two decades. These coatings serve as the first line of defence against attack by an aggressive environment and typically provide protection against surface degradation due to mechanisms such as corrosion, wear/erosion or failure under an excessive heat load (Kvernes et al 1989; Sivakumar 1989). The considerable recent advances in the field of coating technology have been manifested in the form of a wide variety of processes now available to generate protective coatings (Kvernes et al 1988; Rhys-Jones 1990) and a phenomenal rise in the number of powders being specifically developed for thermal spraying applications (Herman 1990).

Of the various coating categories, particularly the ceramic thermal barrier coating (TBC) systems have seen rapid growth. These are recognized to have considerable potential in both aviation and industrial/utility gas turbines as well as in diesel engines (Burgel and Kvernes 1986). The primary purpose of a TBC is to prolong the service life of components operating in a high temperature environment by imparting protection against failure under an excessive heat load. The use of an appropriate TBC system has also been found to considerably improve performance and increase efficiency in heat engines. Furthermore, it virtually eliminates the need for elaborate cooling schemes, and permits substitution of less expensive materials of construction (Miller 1987).

A TBC system generally consists of a metallic bond coat which is oxidation/corrosion resistant at the operating temperature, and a ceramic overcoat. The ceramic coating material selection is largely based on achieving a high level of insulation and a low 
level of interfacial expansion mismatch stress. Properties such as adherence to the bond coat, thermal stress resistance, erosion/wear resistance and stability in the operating environment are also important. Zirconia-based thermal barrier coatings are most widely used because of their low thermal conductivity and relatively high coefficient of thermal expansion (Bennett 1986).

The state-of-the-art TBC for a vast majority of applications is currently a MCrAlY ( $\mathrm{M}=\mathrm{Ni}, \mathrm{Co}, \mathrm{Fe}$ or their combinations) bond coat and an overcoat of zirconia partially stabilized with yttria (Wu et al 1990). The choice of yttria-partially stabilized zirconia (Y-PSZ), is primarily due to its superior mechanical stability during the thermal cycling conditions typically encountered in gas turbine engine environments (Meier et al 1991). Notwithstanding the importance of such coatings to India's own gas turbine engine programme, it remains a fact that indigenously made spray-grade $\mathrm{Y}-\mathrm{PSZ}$ powder is still not available in spite of our vast resources of mineral zircon and rare earths. Apart from the obvious saving in precious foreign exchange currently being expended to import this powder, it is to be noted that the quality of plasma/oxyfuel flame sprayed coatings is greatly dependent on the powder characteristics. It has been reported that the coating quality varies considerably both with the method of powder manufacture and from vendor to vendor (Fairbanks and Hecht 1987). Therefore, the need for an indigenous source of Y-PSZ powder of reproducibly good quality is also as urgent as it is strategically important.

In response to the above requirement, this paper deals with results of a collaborative effort comprising of (i) the preparation of Y-PSZ powder by the sol-gel route at CGCRI and (ii) the evaluation of its suitability for plasma spraying at DMRL. The properties of the above powder and the plasma-sprayed coating obtained from it have also been compared with the corresponding characteristics of an imported Y-PSZ powder and coatings made therefrom.

\section{Sol-gel preparation of Y-PSZ powder}

The sol-gel technique provides a promising means of producing powders having narrow particle size distribution. This technique can also yield spherical particles which ensure good flowability. In addition, the above method is considered cost effective as it involves a relatively low preparative temperature as compared to the other routes available for the synthesis of ceramic powders.

In the present study, a zirconia sol with $\mathrm{Zr}^{4+} / \mathrm{NO}_{3}^{-}$mole ratio of 0.35 was prepared at $90^{\circ} \mathrm{C}$ using $\mathrm{ZrOCl}_{2} \cdot 8 \mathrm{H}_{2} \mathrm{O}$ as the starting material. The sol viscosity was $1.70-1.80 \mathrm{cps}$ and its $\mathrm{pH}$ was $0.35-0.40$. Yttrium nitrate pentahydrate, equivalent to $5 \mathrm{wt} \% \% \mathrm{Y}_{2} \mathrm{O}_{3}$ was added to the above sol. A water-in-oil type emulsion was then prepared by adding appropriate amounts of an organic solvent (1,1,1-trichloroethane) and an emulsifier (Sorbitan monooleate). After allowing an adequate time gap for equilibration, droplets of this emulsion were allowed to react with a suitable organic amine to obtain gel microspheres by the method of external gelation (Wilson and Heathcoat 1990). The presence of the emulsifying agent during this step was found helpful in ensuring particle sphericity. The gel microspheres were washed with methanol, dried at $80^{\circ} \mathrm{C}$ and subsequently heat treated under controlled conditions at $1000^{\circ} \mathrm{C}$ for $1 \mathrm{~h}$ to produce a dense Y-PSZ powder. Approximately $500 \mathrm{~g}$ of Y-PSZ powder was produced in a single batch using the above process. 


\section{Powder characterization}

The suitability of any given powder for spraying applications is primarily governed by its physical properties. Normally, any material that can be melted without decomposing can be sprayed. The quality of a sprayed deposit is also largely dependent upon the powder properties. Among the most important properties of a spray-grade powder are chemical composition, particle shape, particle size distribution and flow characteristics. The determined characteristics of the prepared Y-PSZ powder are briefly discussed below. An imported Y-PSZ powder was also identically tested throughout this study for the purpose of comparison. The two powders were produced by totally different manufacturing routes - the indigenous powder was prepared by using the sol-gel technique and the imported powder was produced by fusing yttria and zirconia in the required proportion.

\subsection{Particle shape}

Specimens of the Y-PSZ powders were mounted, carbon-coated and then observed under a scanning electron microscope (SEM) to ascertain shape and size characteristics of the powders. As the micrographs illustrated in figures $1 \mathrm{a}$ and $\mathrm{b}$ indicate, the indigenous powder consists nearly totally of spherical particles which are predominantly in the $10-50 \mu \mathrm{m}$ size range. On the other hand, the imported powder consists of irregularly shaped angular particles. The noted variation in particle shapes is attributed to the previously mentioned difference in the manufacturing routes for the two powders.

\subsection{Particle size distribution}

The determined particle size distribution of the sol-gel derived powder is shown in figure 2 and is found to corroborate with SEM observation. The $50 \%$ weight average particle size was calculated to be $25.3 \mu \mathrm{m}$. It may be pointed out that an upper particle size limit of $50 \mu \mathrm{m}$ is ideally recommended for ceramic powders intended for plasma spraying applications in order to enable complete melting of particles (Joshi and Sivakumar 1992). This is essential to minimize porosity in the coating. Thus, the indigenous powder is found to satisfy the important particle size requirement for obtaining a high quality coating. Further, the particle size distribution (figure 2) compares well with that of the imported powder. The $50 \%$ weight average particle size of the latter was found to be $23.1 \mu \mathrm{m}$ which differs only slightly from that of the sol-gel produced powder.

\subsection{Flow characteristics}

Good flowability of powder is a much desired characteristic for thermal spray applications. The flow characteristics of the two powders were tested in a Hall flow meter as per ASTM Standard B213-48 (Houck 1982). The indigenous powder appeared to flow well and it was noted that a time of $60 \mathrm{sec}$ was required for $50 \mathrm{~g}$ of the powder to flow through a $2.54 \mathrm{~mm}$ orifice as per the above ASTM standard. In 


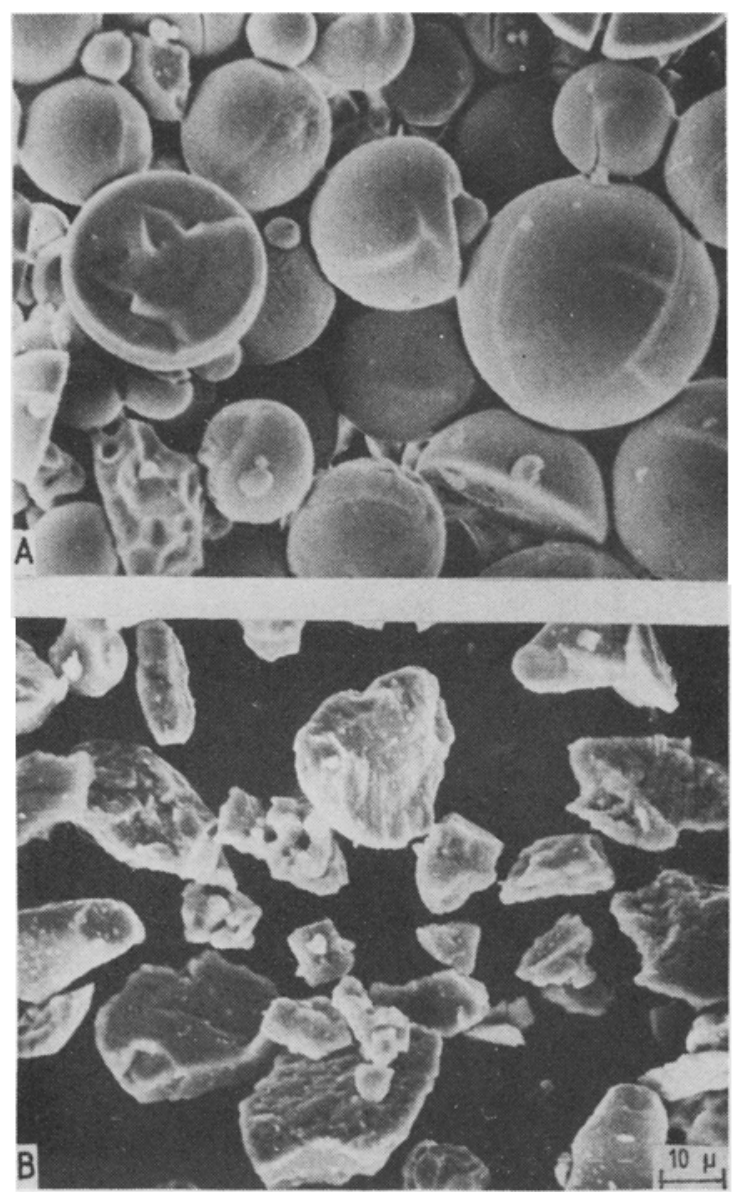

Figure 1. Comparison of morphology of Y-PSZ powders. (A) Indigenous powder (sol-gel derived) and (B) Imported powder (sintered and crushed).

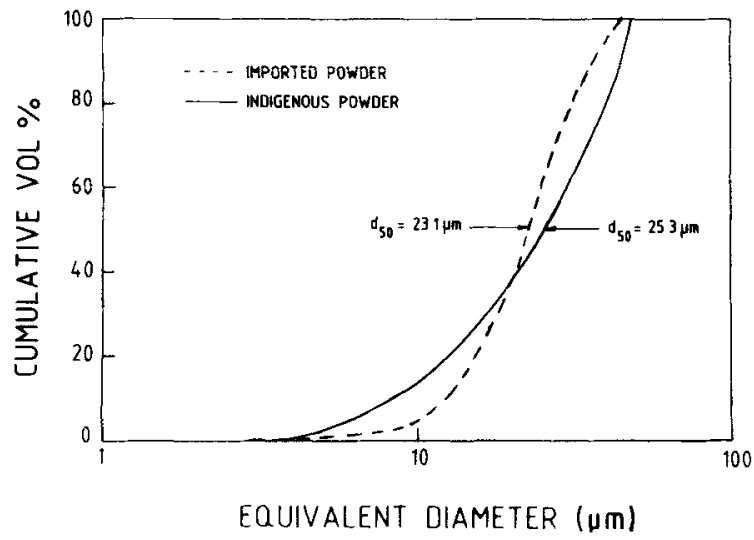

Figure 2. Particle size distributions of the indigenous and imported Y-PSZ powders. 
contrast, it was found that the imported powder did not flow at all in this device. This was due to the difference in particle morphologies of the two powders, with the sol-gel derived powder being free flowing owing to its particle sphericity. While the Hall flow meter is routinely employed to ascertain the flow characteristics of spray grade powders, it is important to mention here that non-flowability in the test device does not preclude a powder from being used for coating applications. Many such powders can be injected into the plasma flame by fluidizing in a carrier gas or made to flow using an air vibrator. However, a free flowing powder is preferable as it aids uniform powder injection into the plasma flame and, thereby, leads to more consistent particle melting and acceleration during spraying.

\subsection{XRD investigation}

X-ray diffraction analysis of Y-PSZ powders was done in order to identify the phases present. The low-angle regions of the general scans of both the powders revealed the presence of only a small amount of monoclinic phase. The mole fraction of the monoclinic phase was determined from the expression (Miller et al 1981)

$$
\frac{M_{m}}{M_{f+t}}=0.82 \frac{I_{m}(111)+I_{m}(11 \overline{1})}{I_{f+t}(111)}
$$

where $M$ refers to the mole fraction of a given phase and $I$, the peak intensity. In the above equation, subscript $m$ denotes the monoclinic phase while $f$ and $t$ denote the cubic and tetragonal phases, respectively. Our calculations, based on XRD patterns obtained, indicate that the monoclinic phase contents in the indigenous and imported Y-PSZ powders were $13.9 \%$ and $14.2 \%$ respectively, the balance being constituted of tetragonal/cubic phases. It may be mentioned here that it was found difficult to resolve the cubic and tetragonal peaks from high-angle slow scans of both the powders and, thus the individual amounts of the two phases could not be separately determined. In any event, as discussed later, it is the monoclinic phase content which can provide valuable information regarding possible disruptive transformations in the Y-PSZ coating during thermal cycling.

\subsection{Chemical analysis}

A wet chemical analysis was also carried out to determine the yttria contents in the two Y-PSZ powders. This was accomplished by dissolving small amount of the powder specimen in an acid medium and analyzing the resulting solution for yttrium using DC plasma emission spectroscopy. Such analysis showed yttria content of $5.07 \%$ in the sol-gel derived Y-PSZ powder. By way of ascertaining the accuracy of the above technique, the imported Y-PSZ powder was also analyzed. It was found to contain $7.94 \%$ yttria, as against a value of $7.44 \%$ provided by the supplier.

\section{Characterization of coatings}

In order to ascertain the suitability of the indigenously produced Y-PSZ powder for plasma spray applications, coatings were developed with this powder using a METCO 
Table 1. Parameters used for plasma spraying of Y-PSZ powders.

\begin{tabular}{lr}
\hline Pressure (psi) & 100 \\
$\quad$ Primary gas (Ar) & 50 \\
Secondary gas $\left(\mathrm{H}_{2}\right)$ & \\
Flow rate (cfh) & 80 \\
$\quad$ Primary gas (Ar) & 15 \\
Secondary gas $\left(\mathrm{H}_{2}\right)$ & 37 \\
Carrier gas (Ar) & 500 \\
Arc current (amps) & $6 \cdot 2$ \\
Powder feed rate (lbs/h) & $2 \cdot 5$ \\
Spray distance (inches) &
\end{tabular}

7MB plasma spray system. Nimonic-75 flats were used as substrates while a $100 \mu \mathrm{m}$ thick plasma sprayed deposit of $\mathrm{Ni}-20 \% \mathrm{Cr}$ was applied as the bond coat. The plasma spray parameters employed for applying Y-PSZ overlayer are indicated in table 1. Small test specimens were cut from the coated Nimonic-75 pieces for metallographic evaluation and XRD analysis of the coating.

\subsection{Metallographic evaluation}

Test specimens of coatings developed using both the Y-PSZ powders were mounted and their cross-sections observed under an optical microscope to determine the extent of porosity in the coatings and to get some idea regarding the adhesion of the ceramic coating to the bond coat. The bonding appeared good in both cases. Typical micrographs of plasma-sprayed ceramic layers are shown in figure 3 . It should be mentioned that the noted porosity in the coatings is reduced as the plasma current is increased (Srivastava et al 1991). However, a current of $500 \mathrm{amps}$ was consistently used throughout this study.

\section{$4.2 X R D$ investigation}

$\mathrm{X}$-ray diffraction analysis of the coatings was also carried out for the purpose of phase identification. As with the powder, both general scan and high-angle slow scan were done using $\mathrm{FeK}_{\alpha}$ radiation. The low angle region of the general scan revealed that the monoclinic phase content was significantly reduced in the course of plasma spraying of the sol-gel derived powder. Using (1), the amount of monoclinic phase was calculated to be about $6 \%$ as compared to nearly $14 \%$ in the starting powder. Consistent with this finding, plasma spraying of the imported powder was also found to reduce monoclinic phase content from above $14 \%$ to only about $3 \%$. It may be mentioned here that, irrespective of the phases present in the starting powder, phase distribution in the sprayed coating is primarily dependent upon the yttria content, the maximum temperature to which the powder particles are heated in the plasma flame and their quenching after impacting the substrate.

As in the case of powders, it was not possible to determine individual amounts of cubic and tetragonal phases due to reasons specified earlier. However, it is pertinent 

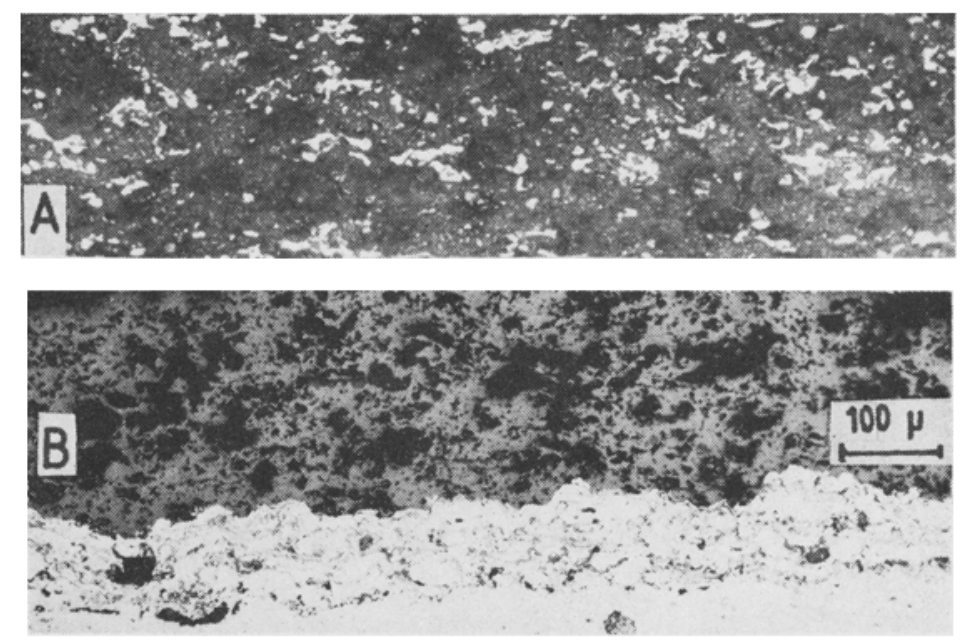

Figure 3. Typical microstructures of the plasma-sprayed coatings (A) using indigenous powder and (B) using imported powder.

to note here that pure zirconia can undergo two solid state phase transformations

$$
\text { monoclinic } \underset{1000 \mathrm{C}}{\stackrel{1170}{\rightleftharpoons} \mathrm{C}} \text { tetragonal } \stackrel{2370^{\circ} \mathrm{C}}{\longleftrightarrow} \text { cubic }
$$

Of these, the tetragonal-to-monoclinic transition during cooling is the disruptive transformation since it is accompanied by a $3-5 \%$ volume increase (Kvernes 1987) that is detrimental to coating life. As such, information regarding individual amounts of the tetragonal and cubic phases may not be as informative or important as monitoring the monoclinic phase content during thermal cycling.

\subsection{Thermal cycling study}

A measure of the thermal shock resistance of an insulating ceramic coating is its life during thermal cycling. Nimonic-75 coupons, each of approximately $15 \times 15 \mathrm{~mm}$ size, were coated for thermal cycling study aimed at assessing thermal shock resistance of the coatings. With each Y-PSZ powder, two sets of thermal cycling specimens were prepared: one set had a $100 \mu \mathrm{m}$ thick NiCr bond coat and a $550 \mu \mathrm{m}$ thick Y-PSZ overlayer while the other had a $100 \mu \mathrm{m}$ thick NiCoCrAlY bond coat and a $300 \mu \mathrm{m}$ thick Y-PSZ overlayer. Each set, consisting of five coated coupons, was subjected to repeated heating and cooling cycles until the coating was found to fail due to cracking or debonding. Each thermal cycle consisted of a 30 -min heating period at $1200^{\circ} \mathrm{C}$ in an air furnace followed by water quench.

This procedure constitutes an accelerated test, the adopted thermal cycle being far more hostile than that experienced in actual operations. The average thermal cycling life of the coatings tested is illustrated in figure 4. The high coating lifetimes obtained, in spite of severe temperature cycle employed in the study, are indicative of good thermal shock resistance. The coatings having a NiCoCrAlY bond coat are more durable than the coatings with a NiCr bond coat (figure 4). This can be attributed 


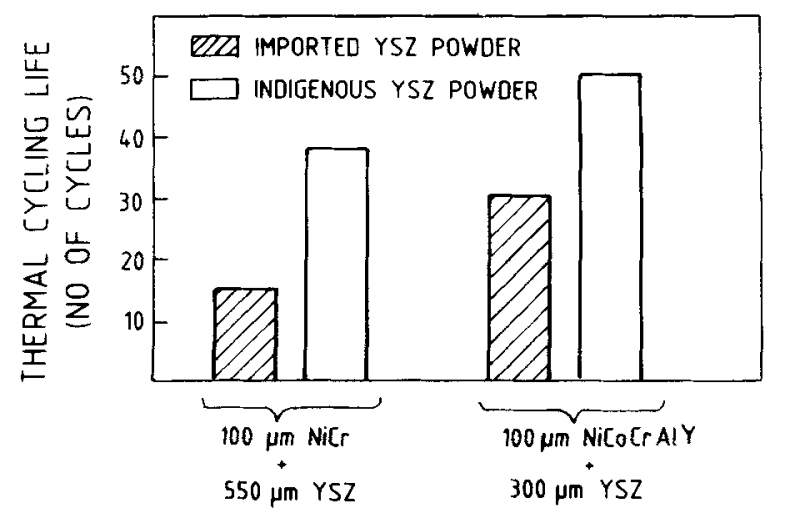

Figure 4. Thermal cycling lifetimes of various coating systems (thermal cycle: $30 \mathrm{~min}$ at $1200^{\circ} \mathrm{C}$ followed by water quench).

to the much better oxidation resistance of the MCrAlY type bond coats (where $\mathrm{M}=\mathrm{Ni}, \mathrm{Co}, \mathrm{Fe}$ or their combinations) than that of $\mathrm{NiCr}$.

It is of particular interest to note, from figure 4 , the higher longevity of coating systems employing the indigenous Y-PSZ powder as compared to similar coatings developed using imported powder. Apart from bond coat oxidation, accumulation of cyclic thermal stresses in the ceramic overlayer plays an important role as far as failure of thermal barrier coatings in high temperature environments is concerned. Figure 5 shows SEM photomicrographs of the as-sprayed coatings obtained using the two Y-PSZ powders. It is seen from this figure that the coating developed with the sol-gel derived powder exhibits fine, limited microcracks while the coating generated using imported powder appears dense with virtually no microcracking detectable. The presence of microcracks provides considerable toughening and increased accommodation of thermal stresses and is presumed to be responsible for the improved durability of coatings formed using the sol-gel derived indigenous powder.

\section{Conclusions}

A spray-grade yttria stabilized zirconia powder indigenously produced by the sol-gel technique and a plasma-sprayed coating developed therefrom have been characterized. An imported Y-PSZ powder and its coating, developed using identical spray parameters, were also evaluated for the purpose of comparison. The following conclusions may be drawn on the basis of the present study:

(i) The indigenous Y-PSZ powder consists nearly totally of spherical particles with an average particle size of about $25 \mu \mathrm{m}$ which is well-suited for plasma spraying.

(ii) The indigenous powder, containing 5.07\% yttria, consists of around $14 \%$ monoclinic phase, the balance being the tetragonal/cubic phases. The monoclinic phase content is found to be reduced during plasma spraying. The same trend is also observed with the imported powder.

(iii) As opposed to the imported powder which did not flow at all through the Hall Flow meter, the indigenous powder appeared to flow well at a rate of $50 \mathrm{~g} / \mathrm{min}$. 

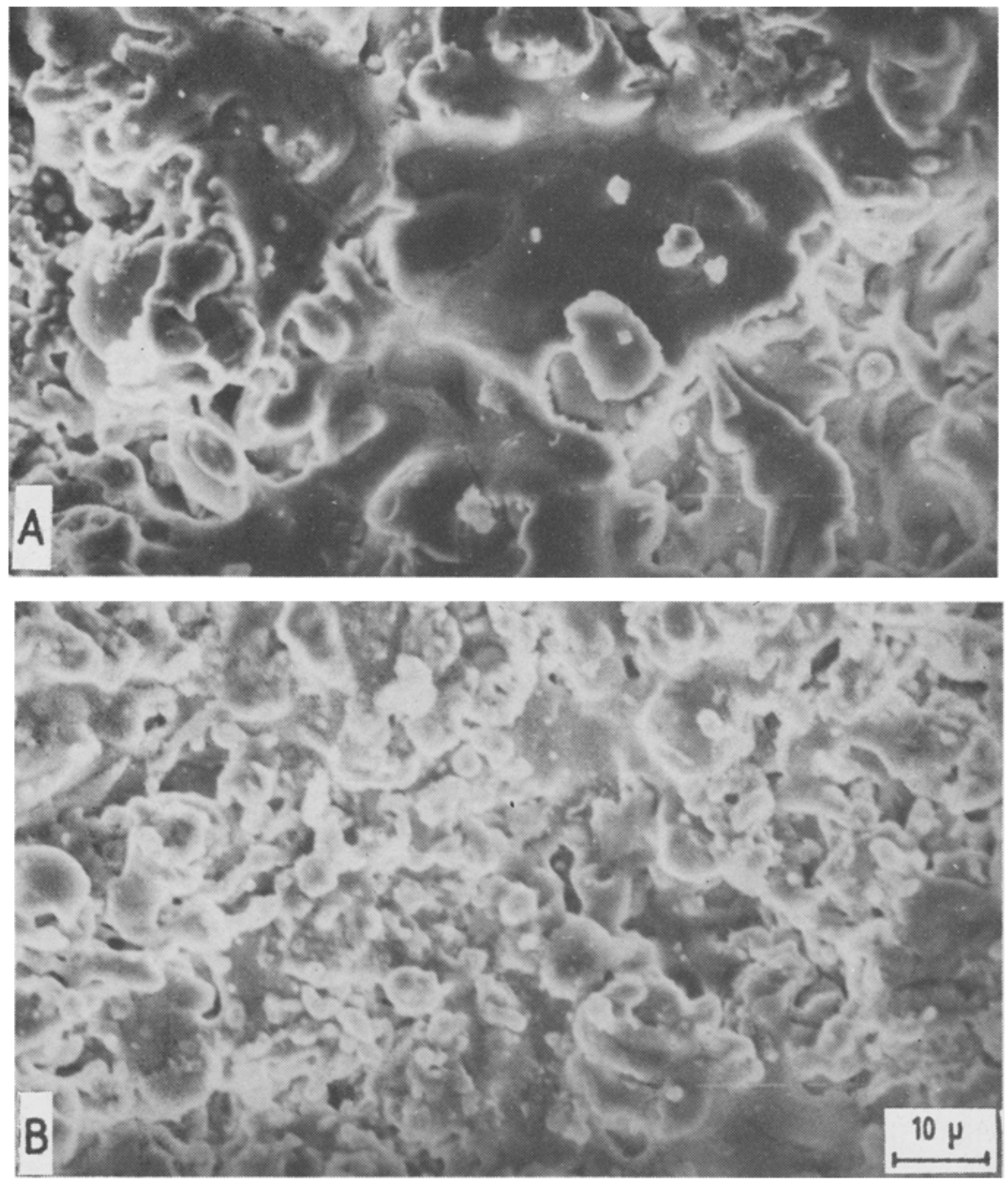

Figure 5. SEM photomicrographs showing surface topography of as-sprayed coatings (A) using indigenous powder and (B) using imported powder.

(iv) A furnace thermal cycling study revealed that the coatings formed using the indigenous powder have good thermal shock resistance. Their longevity was found to be even superior to that of coatings obtained using the imported powder during the thermal cycling test employed in the present study.

\section{Acknowledgement}

The powder synthesis work was carried out at the Central Glass and Ceramic Research Institute (CGCRI) under a Grant-in-Aid scheme of Aeronautical Research and Development Board, Ministry of Defence. The authors of CGCRI are thankful for this financial support. The coatings were prepared and evaluated at the Defence Metallurgical Research Laboratory (DMRL). The authors wish to thank Dr B K Sarkar 
and Mr S L N Acharyulu, Directors of CGCRI and DMRL respectively, for their encouragement and support. They also acknowledge the help of Mr D Jayaram and Mr V S R A Sarma in carrying out the plasma coating and thermal cycling work.

\section{References}

Bennett A 1986 Mater. Sci. Tech. 2257

Burgel R and Kvernes I 1986 in High temperature alloys for gas turbines and other applications (ed.) W Betz (Holland: Reidel Publishing Co.)

Fairbanks J W and Hecht R J 1987 Mater. Sci. Engg. 88321

Herman H 1990 Adv. Mater. Processes 13741

Houck D L 1982 Int. J. Powder Met. Powder Tech. 181

Joshi S V and Sivakumar R 1992 Mater. Sci. Tech. 8481

Kvernes I 1987 in High tech ceramics (ed) P Vincenzini (Amsterdam: Elsevier Science Publishers)

Kvernes I, Espeland M and Norholm O 1988 Scandinavian J. Metall. 178

Kvernes I, Lugscheider E and Lindbolm Y 1989 Proc. 2nd European symp. on engg. cer. (ed) F L Riley (New York: Elsevier Applied Science)

Meier S M, Gupta D K and Sheffler K D 1991 J. Metals 4350

Miller R A, Smialek J L and Garlick R G 1981 in Science and technology of zirconia: advances in ceramics (eds) A H Heuer and L W Hobbs (Westerville, OH: The American Ceramic Society) Vol. 3

Miller R A 1987 Surf. Coat. Tech. 301

Rhys-Jones T N 1990 Surf. Coat. Tech. 421

Sivakumar R 1989 in Powder metallurgy-recent advances (eds) V S Arunachalam and O V Roman (New Delhi: Oxford \& IBH Pub. Co.)

Srivastava M P, Joshi S V, Sarma V S R A, Jayaram D and Sivakumar R 1991 DMRL Technical Report No. 91146

Wilson G and Heathcoat R 1990 Am. Ceram. Soc. Buil. 691137

Wu B C, Chao C H, Chang E and Cnang T C 1990 Mater. Sci. Engg. A124 215 